\section{BASEM Congress 2000}

\section{MORPHOLOGICAL AND PHYSIOLOGICAL CHARACTERISTICS OF ELITE SOUTH AFRICAN BEACH VOLLEYBALL PLAYERS}

S.E.H. Davies, M.F. Coetsee. Department of Human Movement Science, University of Zululand, South Africa

Aim: There appears to be a paucity of research regarding the sport of A2 Man@ beach volleyball (Davies SHE, et al. South African Journal of Sports Medicine 1998;5:13-17).This study investigated the morphological and physiological characteristics of thirteen elite male beach South African (SA) volleyball players, because fitness, physical characteristics and skill are key factors determining performance (Smith DG, et al. Journal of Sports Sciences 1991;10:31-138).

Methods: Parameters measured included stature, mass, percentage body fat, maximal oxygen uptake $\left(\mathrm{VO}_{2} \mathrm{MAX}\right)$, maximal heart rate, and lactate after a treadmill run. All subjects freely volunteered after completing an informed consent form.

Results: The results indicate that elite SA beach volleyball players are generally shorter $185.28 \mathrm{~cm}$ and lighter $82.01 \mathrm{~kg}$ than elite indoor players, and a higher in percentage body fat $13.12 \%$. Their physiological characteristics indicated a mean $\mathrm{VO}_{2} \operatorname{MAX}$ of 59.37 $\mathrm{ml} / \mathrm{kg} / \mathrm{min}$ with a maximal heart rate of $189.38 \mathrm{bpm}$ and lactate measure of $11.87 \mathrm{mmol} / \mathrm{L}$ after a treadmill run to exhaustion.

Conclusions: The results suggest that a lack of emphasis on positional specialisation in beach volleyball appears to have mitigated against the extreme physiques often observed in indoor volleyball players. Interestingly it would seem elite beach volleyball players have superior selected physiological characteristics in terms of $\mathrm{VO}_{2}$ MAX and lactate measures after a maximal treadmill run to exhaustion when compared to indoor players. This would imply that training and playing on sand may have beneficial physiological outcomes when compared to doing similar activities on a hard non-compliant terrain lassuming that there are no major genetic differences between performers).

\section{STRENGTH AND POWER (VERTICAL JUMP PERFORMANCE) CHARACTERISTICS OF ELITE SOUTH AFRICAN BEACH VOLLEYBALL PLAYERS}

S.E.H. Davies, M.F. Coetsee. Department of Human Movement Science, University of Zululand, South Africa

Aim: There appears to be a paucity of research regarding the sport of A2 Man@ beach volleyball (Davies SHE, et al. South African Journal of Sports Medicine 1998:5:13-17). This study investigated the strength and power (vertical jump performance) characteristics of 13 elite male beach South African (SA) volleyball players, because fitness, physical characteristics, and skill are key factors determining performance (Smith DG, et al. Journal of Sports Sciences 1991;10:31-138).

Methods: Parameters measured included stature, mass, percentage body fat, vertical jump performance, and isokinetic measures of peak torque for extension and flexion of both legs at 60, 180, and 240 degrees per second. All subjects freely volunteered after completing an informed consent form.

Results: The results indicate that elite SA beach volleyball players are generally shorter $185.28 \mathrm{~cm}$ and lighter $82.01 \mathrm{~kg}$ than elite indoor players, and a higher in percentage body fat $13.12 \%$. Their jump performance appeared to be modest when compared to other studies with an average of $61.73 \mathrm{~cm}$. Isokinetic peak torque values for leg extension and flexion relative to body mass $(\mathrm{Nm} / \mathrm{kg})$ were for extension at $60 \% \mathrm{~s}=3.29,180 \% \mathrm{~s}=2.37$, and $240 \% \mathrm{~s}=2.0$, and flexion at $60 \% \mathrm{~s}=1.86,180 \% \mathrm{~s}=1.45$ and $240 \% \mathrm{~s}=1.29$.

Conclusions: The results suggest that a lack of emphasis on positional specialisation in beach volleyball appears to have mitigated against the extreme physiques often observed in indoor volleyball players. Interestingly it would seem elite beach volleyball players have superior selected strength characteristics in terms of isokinetic evaluations than cited for most sporting and athletic studies, along with indoor elite volleyball players. One might tentatively suggest that the increased physical demands of running and jumping on sand has beneficial outcomes in terms of increased strength gains. Vertical jump performance however, was lower for elite beach volleyball players, perhaps reflecting the importance of the principle of specificity during training and match play.

\section{PHYSICAL ACTIVITY IN DUBLIN SCHOOLCHILDREN AGED 7-9 YEARS}

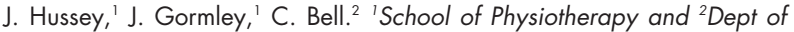
Physiology, Trinity College, Dublin, Ireland.

The aim of this study was to determine physical activity levels in Dublin children between 7 and 9 years of age. Subjects were children attending National Schools in Dublin. A modification of the "Modifiable Activity Questionnaire for Adolescents" was used (Aaron, DJ, et al. Am J Epidemiol 1995;142:191-201). The questionnaire was completed by a parent or guardian. Seven hundred and eighty six questionnaires were analysed ( 352 boys and 434 girls). Participation in 20 minutes of vigorous exercise three or more times per week was done by $39 \%$ with gender differences $28 \%$ of girls and $53 \%$ of boys). Participation in 20 minutes of light exercise three or more times per week was done by $54 \%$ with very small gender differences. Sixty per cent of children were spending 2-3 hours per day in front of a screen (TV, video, PC games). Thirty three per cent were driven to school and $62 \%$ walked some or all of the journey. Fourteen per cent of boys and $24 \%$ of girls were reported to engage in less than the minimal recommendation of regular physical activity as defined by the CDC and ACSM (Sports Med Bull 1994,28:7). Boys participate in more physical activity than girls even at this relatively young age (unpaired $t$ test $\mathrm{p}<0.001$ ). It is reported that many are not undertaking the volume of physical activity necessary to benefit the cardiovascular system.

\section{HORSE RELATED TRAUMA IN A RURAL DISTRICT GENERAL HOSPITAL}

M.A. Quigley, ' S.H. Boyce. ${ }^{2}$ 'Accident and Emergency Department, Dumfries and Galloway Royal Infirmary; ${ }^{2}$ Accident and Emergency Department, Crosshouse Hospital, Kilmarnock

Aim: To determine the characteristics of horse related accidents attending a rural Scottish Accident and Emergency (A\&E) department.

Method: A retrospective case record analysis was undertaken. Relevant cases were identified from the A\&E database by performing a computerised search using "horse", "pony", or "riding" as keywords. The study period was for one year between 1/1/99 and 31/12/99.

Results: Fifty eight horse related accidents were identified (less than $0.2 \%$ of our total workload). Peak attendance was during June and July with $49 \%$ of the total presenting during these 2 months. Forty three $(74 \%)$ were female and $15(26 \%)$ were male. The age range was from four to 78 years and mean age was 26 . Eight of the 58 had to be admitted, three with concussional head injuries, two with lumbar spine fractures, one with neck pain and paraesthesia in upper limbs, one with a soft tissue back injury and one child with a dislocated elbow. Twelve patients required clinic review appointments and 38 were discharged. The sites of main injury were upper limb (22), lower limb (15), back (12), and head (9). There were a total of 15 fractures, 10 of which were to bones of the upper limb. There were no deaths. In 39 patients the mechanism of injury was stated to have been a "fall from horse"; five had been "kicked by horse" and five had been "stood on" or "trampled". Other mechanisms included being bitten, being pushed over or being pulled by the horse.

Conclusion: The volume of work created by horse accidents represents a small proportion of the overall A\&E workload. Females are 2.5 times more likely to attend with horse related accidents than men, and it is still predominantly the young who are injured. The majority of 
injuries are soft tissue. The whole spectrum of trauma was represented from head injuries, chest injuries, blunt abdominal injuries, and limb and spinal fractures. The most frequently injured area was the upper limb and 10 of our 15 fractures were to this region. Protective equipment is unlikely to be effective in these situations. People who work with horses put themselves at risk of injury both in and out of the saddle and although most injuries are of a minor nature there exists the very real potential for serious trauma.

\section{PREVALENCE OF OBSTRUCTIVE AIRFLOW LIMITATION IN COLLEGIATE ATHLETES}

E. Smith, N. Mahony, M. O'Brien. Department of Anatomy, Trinity College, Dublin 2, Ireland

This study investigated the prevalence of obstructive airflow limitation, level of control and inter-sport differences in asthma, in two groups of collegiate athletes, swimmers (SWIM) and endurance athletes, runners and rowers (END)

Ninety eight athletes, 50 male and 48 female, age range 16-28 years completed a respiratory questionnaire and performed spirometry (Microlab 3300, Micro Medical Ltd., UK) to assess FEV, FVC, FEV 1 /FVC and PEFR, pre-exercise and at 5,10 , and 15 min postexercise. Between and within group analyses were carried out using single factor and repeated measures ANOVA, respectively, values of $\mathrm{p}<0.05$ were considered significant.

Previous diagnoses of asthma were reported by $30 \%$ of subjects. The numbers of asthmatics in each sports group is shown in table 1 .

\begin{tabular}{lll}
$\begin{array}{l}\text { Abstract } 5 \\
\text { gender }\end{array}$ & Prevalence of asthma across sport and \\
\hline \multicolumn{4}{l}{} & END & SWIM \\
\hline Male & $25(4)$ & $25(10)$ \\
Female & $23(4)$ & $25(11)$ \\
Total & $48(8)$ & $50(21)$ \\
$\%$ Asthmatics & 8.2 & $21.4^{*}$ \\
\hline
\end{tabular}

Number of asthmatics in parentheses.

"Indicates significance at $p<0.05$ ( $\chi^{2}$ test)

Twenty asthmatics were on treatment; two required intermittent treatment for symptoms precipitated by exercise, cold weather or pollen; four were asymptomatic and no longer required treatment; and three had stopped medication but were symptomatic. All mean FEV, and FVC data, expressed as a percentage predicted, were significantly $(p<0.01)$ greater in SWIM than in END, although SWIM accounted for a significantly greater number of asthmatics.

In conclusion, the majority of athletic asthmatics were adequately controlled, allowing full participation in their chosen sport.

\section{AN INVESTIGATION OF THE USE OF PROTECTIVE EQUIPMENT IN RUGBY UNION FOOTBALL}

C.M. Mannion, ${ }^{1}$ C. Gissane, ${ }^{2}$ N. Henderson, ${ }^{3}$ J.A. White. ${ }^{4}$ 'Centre for Sports Medicine, Department of Orthopaedic and Accident Surgery $C$ Floor, West Block, Queen's Medical Centre, Nottingham NG7 2UH; ${ }^{2}$ Department of Health Studies, Brunel University, Osterley Campus, Isleworth: ${ }^{3}$ Division of Orthopaedic and Accident Surgery, Stoke Mandeville Hospital, Aylesbury, Buckinghamshire; ${ }^{4}$ Division of Public Health Medicine and Epidemiology, D Floor West Block Queen's Medical Centre, Nottingham

Aims: (1) To examine the use of "protective" equipment in elite English Rugby Union Football. (2) To investigate the attitudes, beliefs, and knowledge of players, coaches, clinical sports medicine staff, and referees regarding the current use of "protective" equipment within the laws of the game.

Methods: Self completed survey questionnaires were distributed to all clinical sports medicine staff, coaches, and players among the 12 Allied Dunbar Premiership Division One, Rugby Union Clubs and 10 Senior Referees officiating at this level.

Results: Indicated that coaches, clinical sports medicine staff, and players are aware that "protective" equipment not specified within Law 4 is illegal. However, players are still taking to the field of play wearing illegal "protective" equipment. Players appear to be using this equipment on medical advice, exposure to previous injury, and prevention of injury. However, there was a general opinion that injury could be prevented if referees enforced Law 4 more rigorously.

Conclusions: While there is little scientific evidence for the benefits of "protective" equipment in preventing injuries, its use is widespread in Rugby Union, often in contravention of the law, which may have consequences for players' well being.

\section{PHYSIOLOGICAL COSTS OF A STANDARDISED BOXING TRAINING REGIME}

P.E. Murphy, B. Donne, M. O’Brien. Human Performance Laboratory, Trinity College, Dublin 2, Ireland

We investigated the physiological costs of a 60 min boxing training session relative to maximal and threshold data recorded during an incremental treadmill test to exhaustion in 10 male national competitive boxers. Metabolic $\left(\mathrm{VO}_{2}\right)$ by open circuit spirometry, heart rate (HR) by radio telemetry, and blood lactate (BLa) by fingertip capillary technique data were recorded during treadmill and boxing sessions. The boxing training regime comprised of four by two minute repetitions of abdominal exercises, and six by two minute repetitions of shadow boxing, skipping, and bag work, with a 30 s rest between repetitions. $\mathrm{VO}_{2}$ and $\mathrm{HR}$ data were recorded continuously, and BLa were collected pre, mid, and post-sets of exercise. Data were analysed using ANOVA, values of $\mathrm{p}<0.05$ were considered significant.

Mean (SD) maximal treadmill data were 64.1 (6.5) mL/ $\mathrm{kg} / \mathrm{min}$ and 193 (10) beats/min for $\mathrm{VO}_{2}$ and HR respectively. Table 1 presents the mean results for the training session as percentage of maximal and threshold data. Abdominal, shadow, and skipping exercises elicited $\mathrm{HR}$ and $\mathrm{VO}_{2}$ responses significantly $(\mathrm{p}<0.001)$ lower than at $\mathrm{T}_{\text {loc }}$ while $\mathrm{VO}_{2}$ for bag work was lower $(p<0.05)$ than at $\mathrm{T}_{\text {lac }}$. All boxing exercises (except abdominal) met criteria outlined by the ACSM for increasing individual aerobic threshold.

Abstract 7 Mean (SD) data for training session as percentage of max and that at $T_{\text {lac }}$

\begin{tabular}{|c|c|c|c|c|}
\hline & \multicolumn{4}{|l|}{ Mean (SD) } \\
\hline & $\% \mathrm{HR}$ at $\mathrm{T}_{\text {Lac }}$ & $\% \mathrm{HRmax}$ & $\% \mathrm{VO}_{2}$ at $\mathrm{T}_{\text {Lac }}$ & $\% \mathrm{VO}_{2 \max }$ \\
\hline Abdominal & $65.5(6.7)$ & $59.3(7.0)$ & $36.1(8.6)$ & $30.1(6.5)$ \\
\hline Shadow & 89.7 (7.3) & 80.7 (5.7) & $79.2(15.1)$ & 66.1 (11.4) \\
\hline Skipping & $92.1(16.4)$ & $82.9(5.3)$ & 76.2 (8.8) & 63.8 (7.7) \\
\hline Bag work & $101.7(5.7)$ & $90.8(3.5)$ & $90.1(8.5)$ & 75.5 (7.0) \\
\hline
\end{tabular}

\section{A SURVEY OF SPORTS INJURIES ATTENDING AN ACCIDENT \& EMERGENCY DEPARTMENT}

S.H. Boyce, ${ }^{1}$ M.A. Quigley. ${ }^{2}$ Accident and Emergency Department, Crosshouse Hospital, Kilmarnock; ${ }^{2}$ Accident and Emergency Department, Dumfries and Galloway Royal Infirmary

Aim: To assess the frequency, type of injury, sport involved, and management of sports injuries in patients attending an Accident \& Emergency (A\&E) department.

Method: All patients, aged 16 years and over, presenting with an injury related to sport, were studied prospectively over a period of three months.

Results: During the study period, 273 patients attended the A\&E department with a sports injury. This represented $2.3 \%$ of the departments overall workload. Males $(89 \%)$ were injured more frequently than females $(11 \%)$. Injury rates in both males and females peaked in the 16-20 age category. Football was the most common sport implicated in injuries $(65 \%)$. Rugby $(6.6 \%)$, basketball $(3.3 \%)$ and badminton $(2.5 \%)$ were the next most frequently involved sports. Soft tissue injuries dominated $(70 \%)$. The lower limb was the most common anatomical area injured $(60 \%)$. Other injuries involved the upper $\operatorname{limb}$ $(25 \%)$, head and neck $(10 \%)$, and the trunk $(4 \%)$. Ankle sprains were the most common injury (19\%). The majority of patients were referred to their general practitioner for review $(61 \%) .25 \%$ were reviewed at out patient clinics, $5 \%$ were referred for physiotherapy, and $3 \%$ required hospital admission. The remainder required no follow up. 
Two cardiac arrests are reported, one during a football game, the other whilst swimming. One of these patients died, the other was resuscitated but suffered significant brain damage.

Conclusion: Many people participate in exercise and sporting activities. In pursuing an active lifestyle they can suffer injury. Management of the sports injured patient presents different problems to the clinician as patients often wish to return their sport as soon as possible. A greater emphasis should be placed on the prevention of injury and the use of hospital specialists, sports injury clinics, and physiotherapy during the rehabilitation process.

\section{SPORTS INJURY CLINICS ON THE NHS: A PATIENT SURVEY}

S.H. Boyce, 'M.A. Quigley. ${ }^{2}$ 'Accident and Emergency Department, Crosshouse Hospital, Kilmarnock; ' ${ }^{2}$ ccident and Emergency Department, Dumfries and Galloway Royal Infirmary

Aim: To determine patients attitude to the treatment of their sports injury and whether they would prefer follow up at a Sports Injury Clinic within the National Health Service (NHS).

Method: Forty people were selected at random from patients attending the Accident \& Emergency (A\&E) department of Crosshouse hospital, Kilmarnock, with a sports injury who were discharged to the care of their general practitioner (GP) for follow up. A questionnaire was sent to each patient asking two questions: were you happy with the treatment you received in the A\&E department? If a specialised sports injury clinic was present at the hospital would you have preferred your injury to have received further treatment at this clinic rather than your local GP practice?

Results: A response rate of $47.5 \%$ was obtained. Eighty nine per cent of patients were happy with the treatment they received in the A\&E department. The reason given for dissatisfaction was the waiting time and not the specific treatment of their injury. Eighty nine per cent also would have preferred their injury to be reviewed at a sports injury clinic and not their GP practice. The reasons given for this will be outlined.

Conclusion: The overwhelming majority of patients attending A\&E with a sports injury in this survey would prefer to have their follow up care by specialists at a sports injury clinic within their local hospital.

\section{DOES LIVE TV FOOTBALL AFFECT ATTENDANCES AT ACCIDENT AND EMERGENCY DEPARTMENTS?}

S.H. Boyce. Accident and Emergency Department, Crosshouse Hospital, Kilmarnock

Aim: To determine if live terrestrial television football broadcasts affect patient attendance at an Accident \& Emergency (A\&E) department.

Method: Glasgow Rangers football club, the Scottish league champions, were competing in the European Champions League season $1999 / 2000$. The competition was played for six weeks, either on a Tuesday or Wednesday evening.

The matches were broadcast live on Scottish television, the programme commencing at $19: 30$ and ending at 22:00. Patients attending the A\&E department during these hours on each match night were noted prospectively. Only self presenting patients were noted. All specialty receiving patients were excluded. The patients attending on all other week nights during these hours were noted and a weekly average figure calculated.

Results: Table 1 highlights the results obtained:

\begin{tabular}{lll}
\hline Abstract 10 & & \\
\hline Champions League & Patients attending & $\begin{array}{l}\text { Average patient } \\
\text { attendance }\end{array}$ \\
\hline Week 1 & 10 & 15.7 \\
Week 2 & 14 & 16 \\
Week 3 & 12 & 14.3 \\
Week 4 & 16 & 14.1 \\
Week 5 & 18 & 15 \\
Week 6 & 8 & 15.7 \\
\hline
\end{tabular}

week 1, A; week 2, $\mathrm{H}$; week 3, $\mathrm{H}$; week 4, $\mathrm{A}$; Week $5, \mathrm{H}$; week 6 ,
The following bar chart represents the difference in attendance on match nights compared to other evenings.

\section{Attendance during live TV football}

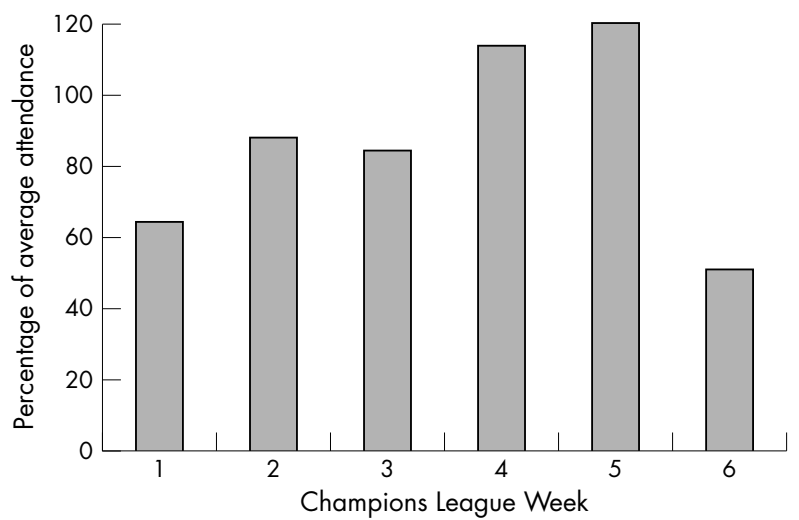

Conclusion: The results demonstrate that there is an apparent decrease in patient attendance during match nights, although not exclusively. Other factors - for example, weather and time of year, also require consideration.

\section{THE EFFECT OF OVERHEAD SPORTS ON STATIC SCAPULAR POSITION}

D.R. Simpson, K.T. Boyd. Centre for Sports Medicine, Queen's Medical Centre, Nottingham

Anecdotally, postural adaptations around the shoulder are frequently seen in overhead sporting athletes. Clinically, abnormal scapular positioning is felt to be associated with shoulder impingement. The main aims of the study were: (1) To quantify the effect of overhead sports on static scapular position, (2) Determine the clinical usefulness of such measurements.

Three cohorts of subjects (aged 16-25 years) were evaluated, swimmers $(n=35)$, tennis players $(n=32)$, and controls $(n=33)$. The scapular position was determined using the method described by DiVeta et al (Phys Ther 1990;70:470-9). Measurements included scapular distance (T3 to inferior angle of acromion), scapular size (medial border of scapula to inferior angle of acromion), and an additional anterior distance (sternoclavicular joint to inferior angle of acromion).

The results were analysed using ANOVA and an independent $t$ test. Scapular distance was significantly increased in the dominant shoulder in tennis players $(p<0.05)$ and in both shoulders in swimmers $(p<0.01)$ compared with controls. DiVeta's normalised ratio and our new anterior/posterior ratio failed to show significant differences. The incidence of shoulder pain did appear to be related to the degree of scapula abduction, but not at a significant level.

Our findings suggest quantifiable postural adaptations do occur as a result of overhead sports. These measurements are easy to perform and could be used to monitor athletes during rehabilitation.

\section{QUESTIONNAIRE BASED STUDY OF ATTITUDES OF COACHES AND PHYSIOTHERAPISTS TO WARM UP AND WARM DOWN IN THREE SPORTS}

A. Naushad.

Objective: To determine the attitudes of medical and coaching staff working with elite performers to warm up and warm down in three team sports.

Methods: Questionnaires were sent to 40 male football clubs, 37 female football clubs, 50 male rugby clubs, 50 male hockey clubs, and 107 female hockey clubs across Scotland. Two questionnaires were sent to each club, one to be completed by the coach and the other by the physiotherapist.

Results: In total, 176 Replies were received: $42 \%$ from coaches and $20 \%$ from physiotherapists. Warm up was regularly used by $90 \%$ of clubs. Over $90 \%$ of coaches and physiotherapists believed from personal experience that warming up enhanced performance and 
reduced the risk of injury. Eighteen per cent to $35 \%$ of clubs in different sports always warmed down, while those who never warmed down ranged from $10 \%$ to $32 \%$. Fifty eight per cent of coaches and $74 \%$ of physiotherapists felt that warming down enhanced subsequent performance, while $76 \%$ of coaches and $79 \%$ of physiotherapists believed that this practice reduced the risk of injury. The main reasons highlighted for not warming down were that there was not enough time $(26 \%)$ and that players were told not to do so $(26 \%)$. Overall the majority of coaches $(53 \%)$ and physiotherapists $(72 \%)$ believed that warm up and warm down were of equal importance.

Conclusion: Coaches and physiotherapists seem convinced of the benefits of warm up. However, uncertainty still surrounds the issue of warm down, although it does appear that more coaches and physiotherapists are accepting the value of this practice.

\section{A SIX WEEK HOME EXERCISE PROGRAMME FOR INDIVIDUALS WITH CHRONIC OBSTRUCTIVE PULMONARY DISEASE}

L. Barr.

Background: Chronic Obstructive Pulmonary Disease (COPD) is a non-specific term used to describe airflow obstruction diseases of the lungs. It is the fifth leading cause of morbidity in the USA and is a primary cause of death for all ages in the UK.

Methods: Seven individuals, four males and three females from the pulmonary rehabilitation list of one Glasgow Hospital agreed to participate in this six week home exercise study. Each individual completed two baseline tests-a six minute Walking Test and an Activities of Daily Living Test (ADL) together with The Breathing Problems Questionnaire. The individuals were then randomised into an exercise and control group. The exercise group followed a six week graduated walking and muscle strengthening programme, with the controls continuing with their normal ADL. At completion of the six week home exercise programme, all individuals were retested. The results of the exercise group suggested an improvement in the walking test and the ADL tests had occurred, however, no statistical significance was observed. The results of the control group showed that two of the subjects showed an improvement in their walking distance, but again no statistical significance was observed. The controls also recorded slower ADL tests as well as higher questionnaire scores, but these findings were also not significant.

Conclusion: This study should therefore be viewed as a pilot study in assessing the benefits of a six week home exercise programme for individuals with COPD.

\section{THE MEASUREMENT OF PHYSICAL ACTIVITY IN A GROUP OF CARDIAC PATIENTS}

T. Thompson.

Objective: The purpose of this study was to examine the relationship between activity counts (CSA accelerometer) and energy expenditure $\left(\mathrm{VO}_{2}\right)$ measured during various walking speeds and daily living activities in a group of cardiac patients.

Methods: Fifteen cardiac patients (13M, 2F; age 59.6 (6.3)) participated in the study. Patients walked at three different speeds (slow, normal, and brisk) and completed daily living activities (hoovering, walking with loaded shopping bags, and pushing a loaded trolley) for six minutes. Energy expenditure $\left(\mathrm{VO}_{2} \mathrm{ml} / \mathrm{kg} / \mathrm{min}\right)$ was measured using a portable metabolic system (Cosmed $\left.\mathrm{K} \mathrm{b}^{2}\right)$. Activity counts were collected using CSA accelerometers worn on the waist, ankle, and wrist.

Results: There was a significant increase in mean activity counts (waist) and mean $\mathrm{VO}_{2}$ as walking speed increased (Table l). Mean activity counts (waist) and $\mathrm{VO}_{2}$ for the daily living activities are presented in Table 2. Mean $\mathrm{VO}_{2} \mathrm{ml} / \mathrm{kg} / \mathrm{min}$ measured during these activities are similar however the activity counts collected are significantly different.

Abstract 14 Table 1 Mean activity counts and mean $\mathrm{VO} 2 \mathrm{ml} / \mathrm{kg} / \mathrm{min}$

\begin{tabular}{lll}
\hline Walking speed & $\begin{array}{l}98 \% \mathrm{Cl} \text { for activity } \\
\text { counts }\end{array}$ & $\begin{array}{l}98 \% \mathrm{Cl} \text { for } \\
\mathrm{VO} 2 \mathrm{ml} / \mathrm{kg} / \mathrm{min}\end{array}$ \\
\hline Slow-normal & -1227 to -734 & -2.221 to -1.182 \\
Normal-brisk & -2747 to -1703 & -6.977 to -4.706 \\
\hline
\end{tabular}

Abstract 14 Table 2 Activity counts and $\mathrm{VO} 2 \mathrm{ml} / \mathrm{kg} / \mathrm{min}$ during daily living activities

\begin{tabular}{lll}
\hline Activity & Activity counts & VO2 ml/kg/min \\
\hline Hoovering & $337(406)$ & $10.51(3.14)$ \\
Shopping bags & $2184(564)$ & $12.32(1.62)$ \\
Shopping trolley & $1881(591)$ & $12.56(2.48)$ \\
\hline
\end{tabular}

Discussion: The CSA accelerometer worn at the waist can differentiate changes in walking speed but not daily living activities.

\section{EXERCISE CAPACITY IN PATIENTS WITH AN ATRIAL SEPTAL DEFECT OR PATENT FORAMEN OVALE}

D. Wilson.

Objective: To measure the total oxygen consumption in patients before and 4 weeks after transcatheter closure of an ostium secundum type ASD or Patent Foramen Ovale (PFO).

Methods: The study was performed as a joint prospective and retrospective study. Eight consecutive patients who underwent transcatheter ASD closure between January and March 2000 were included. All patients underwent a symptom limited exercise test, transthoracic echocardiography (TTE), and TTE/transcranial Doppler ultrasonography (TCD) pre and at 4 week post closure. Blood samples were taken from the subjects pre, $24 \mathrm{hrs}, 7$ days, and 4 weeks (+1 week). A further 15 patients who previously undergone transcatheter ASD closure were invited for a symptom-limited exercise test, TTE/TCD (including bubble tests).

Results: The prospective patients had a significantly decreased $\mathrm{VO}_{2} \operatorname{MAX}(p=0.0069)$ and there was no significant difference between pre and post-closure values $(p=0.757)$. There was no significant difference between predicted and measured $\mathrm{VO}_{2} \mathrm{MAX}$ in the retrospective study. There was no significant change in right ventricle (RV) diameter pre and post-closure in either the prospective or retrospective group $(p=0.128 ; p=0.126)$. There was significant correlation between shunt and device size $(p=0.045)$ and between preclosure RV diameter and shunt size $(p=0.001)$.

Conclusion: The device efficiently prevented right-to-left shunting in the majority of patients. The results are similar to those obtained by previous studies on ASD closure. This pilot study suggests the need for a prospective longitudinal study in this group.

\section{COMPARISON OF TWO FIELD TESTS WITH A LACTATE THRESHOLD TEST IN SEMI PROFESSIONAL SCOTTISH FOOTBALLERS}

N. MacLeod.

The primary aim of this study was to see whether a suitable field test could be found which gives an accurate indication of aerobic fitness levels in a group of semi professional footballers. To do this, the results from a multistage shuttle test (20-MST) and the Cooper test were compared to a laboratory lactate threshold test. A secondary aim was to compare the aerobic fitness levels of the players in mid-season with their pre-season values. The results showed no significant difference between the pre and mid-season 20-MST scores (-2.75-2.25 C.I. $95 \%$ ). The correlation between the 20-MST and the treadmill test was 0.857 with a $p$ value of 0.003 . The correlation between the Cooper test and the treadmill test was 0.222 with a $p$ value of 0.565 .

These findings suggest that there was no difference between the aerobic fitness levels of these footballers between pre and mid-season. They also indicate that fitness levels assessed by the 20-MST correlate well with the treadmill assessment whereas the Cooper test did not have a significant correlation with the treadmill test. This suggests that the 20-MST is an appropriate test to use to monitor the fitness levels of footballers throughout the season.

\section{OSTEOARTHRITIS-THE EFFECTS OF EXERCISE HISTORY, CORTICOSTEROID INJECTIONS, AND INJURY IN FOOTBALL PLAYERS}

R. Chaudry.

Aims: To determine whether exercise history, use of corticosteroid injections, previous injury and playing surfaces increase the risk of developing osteoarthritis $(\mathrm{OA})$ of the knee in ex-professional footballers. 
Subjects and Methods: Nine hundred questionnaires were sent out to ex-professional Scottish footballers registered with the Scottish Football Association (SFA). Questions covered personal details including occupation, exercise history, injury history, playing surfaces, use of steroid injections, and current symptoms. Subjects were divided into three groups: those with clinically/radiographically diagnosed $O A$ (Group 2), those with symptoms of OA (Group 1), and those with no present symptoms (Group 0).

Results: No significant difference was found between the three groups with respect to exercise history and playing surface $(p=0.322$ and 0.055 respectively). Number of steroid injections received was found to be a significant risk factor for $O A(p=0.002)$; those with $O A$ had received significantly more injections compared to subjects with symptoms, $\mathrm{Cl}(0.076,3.813)$ and those without, $\mathrm{Cl}(0.911,4.501)$. Previous knee injury was also found to significantly increase risk of $O A$ development $(p=0.003$ and $p=0.15$ for right and left knees respectively). The most significant differences were seen in cartilage injuries in both knees $(p=0.000$ and $p=0.006$ right and left respectively).

Conclusion: The use of intra-articular steroid injections in treating knee injuries does appear to increase risk for OA suggesting caution in their future use until more research is carried out. All types of injury were found to increase risk of joint degeneration including those to the collateral and cruciate ligaments although injury to the cartilage (menisci) carried the greatest risk.

\section{THE EFFECTS OF ANKLE BRACING ON ELITE BADMINTON PLAYERS (PRELIMINARY REPORT)}

K. McEwan. Department of Biological Sciences, University of Stirling, Stirling FK9 4LA

The effects of three types of ankle braces on indices of performance, specific to badminton, and on ankle range of movement (ROM) of six Scottish international players have been investigated.

Badminton specific performance tests (vertical jump height, lunge length, and speed test (Chin MK, et al. Br J Sports Med 1995:29: 153-7)| were measured in unrestrained players and when wearing each type of brace bilaterally. Ankle ROM was also measured consecutively for each subject without braces, immediately after each brace application and following a 15 minute badminton game (braces in situ) using the Kincom isokinetic dynamometer. Bracing did not appear to significantly affect any performance tests. In ankle ROM tests, inversion was significantly reduced by all ankle braces, even following a 15 minute badminton game. Braces also seemed to have a small but significant effect on dorsiflexion and plantarflexion. Eversion, on the other hand, was not significantly affected by any type of brace.

It is concluded from these preliminary investigations that all three types of braces, performed their primary function in restricting ankle inversion and should be effective, therefore, in preventing lateral ligament injuries in badminton players. Eversion appeared not to be significantly affected by any of the braces and consequently may be less effective in preventing medial ligament injuries. Although dorsiflexion and plantarflexion ROM appeared to be affected by bracing, this apparent limitation did not seem to effect performance.

\section{A RANDOMISED CONTROLLED STUDY OF PHYSICAL ACTIVITY AS AN ADJUNCTIVE TREATMENT FOR CLINICALLY DEPRESSED PATIENTS IN A PRIMARY CARE SETTING}

\section{A.M. Campbell, A. McGinlay, T. Saunders, N. Mutrie.}

This study investigated moderate exercise as an adjunctive treatment for patients undergoing usual care for depression in a primary care setting. Instruments used were the Beck Depression Inventory (BDI), Scottish Physical Activity Questionnaire (SPAQ) and the Profile of Moods-Bipolar Form (POMS). The study was a two group by four timepoint randomised controlled trial of eight weeks duration. The two groups were exercise plus usual care (exercise group) and usual care (control group). Seventeen participants were randomly assigned to either the exercise or control groups. Three participants dropped out of the exercise group. Two sample and paired $t$ tests and non-parametric tests were employed to analyse the results. No significant differences were obtained between groups on the BDI, POMS, or $S P A Q$ at the end of the eight week period. Due to the small sample size and the drop out of three participants assigned to the exercise group, it was concluded that exercise as an adjunctive treatment for depression was not significantly effective with this test group. However, implications for further research include strategies for managing difficulties with recruitment and adaptations to exclusionary criteria.

\section{IMMUNOLOGICAL RESPONSE TO A TRAINING MICROCYCLE IN ENDURANCE TRAINED COLLEGIATE ROWERS}

N. Mahony', B. Donne ${ }^{2}$, P. Kelly ${ }^{3}$, M. O'Brien.' 'Department of Anatomy \& ${ }^{2}$ Department of Physiology, Trinity College, Dublin; ${ }^{3}$ Department of Immunology, St James's Hospital, Dublin, Ireland

The study investigated short term immunological responses to a typical rowing training microcycle.

Eight endurance trained male rowers underwent incremental ergometer test to determine blood lactate response to exercise. Individual load at lactate threshold, interpolated graphically, determined workloads for subsequent supervised weekly ergometer training schedule of three by (steady state $(S)$, long distance $(E)$, and high intensity $(H))$. Duration of $E$ and $H$ equated to work done in $S$ and alternated daily with rowing on water (60 min E). Blood samples were taken for immunological assay, pre, one, and two hours post-exercise at final weekly training sessions. Post-exercise cell counts were expressed as percentage of pre-exercise value for T cells, NK cells, and total lymphocyte count.

Mean per cent reductions are shown in Table 1. Pre-exercise values were similar across the microcycle. NK cells were significantly reduced one and two hours post-exercise for $S, E$, and $H$; T cell and total lymphocyte count showed significant reductions for $\mathrm{S}$ and $\mathrm{H}$ but not $\mathrm{E}$.

Rowing ergometer training $\mathrm{S}, \mathrm{E}$, and $\mathrm{H}$ (duration $<45 \mathrm{~min}$; three per week) alternating with active recovery (60 min E) showed no cumulative reduction in cell counts over each week or over the entire microcycle.

\section{AN EVALUATION OF A GENERAL PRACTICE EXERCISE REFERRAL SCHEME FOR HIGH RISK PATIENTS WITH CORONARY HEART DISEASE}

M.D. Wigglesworth, P. Maclntyre, W.S. Hillis. Department of Medicine and Therapeutics, Gardiner Institute, Western Infirmary, Glasgow G11 6NT, UK.

Aim: To determine whether participation in a primary care based exercise referral scheme leads to a change in exercise tolerance time or physical activity behaviour in patients with established coronary heart disease.

Methods: Sixty adults (mean age 63 years) were followed up 4-16 months after referral to a GP exercise referral scheme. Subjects underwent an exercise tolerance test and completed a physical activity questionnaire. The results were compared retrospectively to pre-participation data.

Abstract 20 Mean \% reduction in T cell, NK cell \& Total Lymphocyte counts from pre-exercise value for steady (S), easy $(\mathrm{E})$ and high intensity $(\mathrm{H})$ rowing ergometer training.

\begin{tabular}{|c|c|c|c|c|c|c|c|c|c|}
\hline & \multicolumn{3}{|c|}{$\%$ reduction NK cells } & \multicolumn{3}{|c|}{$\%$ reduction T cells } & \multicolumn{3}{|c|}{$\%$ reduction Total Lymphocytes } \\
\hline & $\mathrm{s}$ & $\mathrm{E}$ & $\mathrm{H}$ & S & $\mathrm{E}$ & $\mathrm{H}$ & S & $\mathrm{E}$ & $\mathrm{H}$ \\
\hline$+1 \mathrm{~h}$ & $71^{\circ}$ & $60^{\circ}$ & $78^{\circ}$ & $19^{\circ}$ & 8 & $26^{*}$ & $26^{*}$ & 14 & 34 * \\
\hline$+2 h$ & $49^{\circ}$ & $47^{*}$ & $49^{\circ}$ & $16^{*}$ & 2 & $26^{*}$ & $21^{*}$ & 9 & 31 * \\
\hline
\end{tabular}

"Denotes significant reduction from pre-exercise value using Scheffe $F$ test, $(p<0.05)$. 
Abstract 22 Mean (SEM) for selected variables at 8,10 , and $12 \mathrm{~km} / \mathrm{hr}$ for wire gauze and visor fencing masks

\begin{tabular}{|c|c|c|c|c|c|c|c|c|c|}
\hline \multirow{2}{*}{$\begin{array}{l}\text { Velocity } \\
(\mathrm{km} / \mathrm{hr})\end{array}$} & \multicolumn{3}{|c|}{$\mathrm{VO}_{2}(\mathrm{ml} / \mathrm{kg} / \mathrm{min})$} & \multicolumn{3}{|l|}{$\mathrm{PiO}_{2}(\mathrm{~mm} \mathrm{Hg})$} & \multicolumn{3}{|c|}{$\mathrm{PiCO}_{2}(\mathrm{~mm} \mathrm{Hg})$} \\
\hline & 8 & 10 & 12 & 8 & 10 & 12 & 8 & 10 & 12 \\
\hline Wire gauze & $29.8(1.4)$ & 34.1 (1.9) & $38.1(1.5)$ & $153.5(1.1)$ & $153.5(0.8)$ & $153.2(1.0)$ & $3.4(0.6)$ & $3.4(0.7)$ & $3.5(0.7)$ \\
\hline Visor 1 & $31.0(1.9)$ & $35.1(2.0)$ & $38.6(2.0)$ & $148.2(1.1)^{*}$ & $148.2(0.7)^{*}$ & $148.9(0.9)^{*}$ & $7.6(0.7) \dagger$ & $8.6+(0.7) t$ & $8.2(0.8) \dagger$ \\
\hline Visor 2 & $29.8(2.3)$ & $35.1(2.7)$ & $39.3(3.4)$ & $148.2(1.0)^{*}$ & $148.9(0.8)^{*}$ & $148.9(0.9)^{*}$ & $7.7(0.7)$ & $8.4(0.6) \dagger$ & $9.1(0.8) \dagger$ \\
\hline
\end{tabular}

Results: Thirty eight patients had taken part in the exercise scheme. The number of physically active individuals increased between referral and follow up (14 v 24; $p=0.02)$. There was an increase in the number of minutes of moderate or vigorous activity performed in the previous week (170 ₹ 357; $<<0.001)$. Exercise tolerance time (min/ sec) increased in the most active group of participants from $7^{\prime} 13$ to $8^{\prime} 06(p=0.04)$. No differences in exercise tolerance time were found for less active participants or for non-attenders. There were no changes in the frequency or extent of exercise induced ischaemia after taking part in the exercise scheme.

Conclusions: Participation in a primary care-based exercise referral scheme can lead to an improvement in physical activity behaviour and functional capacity in patients with coronary heart disease.

\section{NEWLY DESIGNED FENCING FACE MASKS: EFFECTS ON CARDIORESPIRATORY COSTS AND SUB-MAXIMAL PERFORMANCE}

A. Daya, B. Donne, M. O'Brien. Human Performance Laboratory, Trinity College Dublin, Dublin 2, Ireland

We investigated the cardiorespiratory costs of polycarbonate visor and wire gauze fencing masks in nine male collegiate/national level fencers during sub-maximal treadmill exercise. Metabolic $\left(\mathrm{VO}_{2}, \mathrm{VE}\right.$, and RER) by open circuit spirometry, heart rate (HR) by radio telemetry, and blood lactate (BLa) by fingertip capillary technique data were recorded during both incremental and sub-maximal treadmill $(8,10$, and $12 \mathrm{~km} / \mathrm{hr}$ ) tests. Mask order was randomly assigned during sub-maximal tests, $\mathrm{PiO}_{2}$ and $\mathrm{PiCO}_{2}$ were monitored, and a fencing specific questionnaire completed. Group results were presented as mean \pm SEM and analysed using a two way repeated measures ANOVA, values of $p<0.05$ were considered statistically significant.

Mean $\mathrm{VO}_{2} \mathrm{MAX}$ was $59.3 \pm 2.0 \mathrm{ml} / \mathrm{kg} / \mathrm{min}$. Mean $\mathrm{PiO}_{2}$ was significantly reduced and mean $\mathrm{PiCO}_{2}$ significantly increased when wearing the visor fencing masks, $p<0.01$ see table 1 . The mild level of induced hypoxia did not effect performance variables, no significant effects on sub-maximal metabolic, cardiovascular or blood lactate data were associated with the different fencing masks ( $p>0.05$, see table 1). The questionnaire revealed concerns about the expense, safety, and visual attributes of the new visor masks.

In conclusion, visor fencing masks did not elicit higher cardiorespiratory costs during sub-maximal exercise under the mildly induced hypoxic conditions recorded.

\section{FACTORS INFLUENCING THE UPTAKE AND ADHERENCE TO A COMMUNITY BASED EXERCISE REFERRAL PROGRAM (LIVING PLUS)}

S. Parkhill.

Background/Aims: A questionnaire was designed to assess uptake, adherence, reasons for drop out, barriers to participation, and physical activity levels in all patients who were referred by their GP's to a community based exercise program called 'Living Plus'.

Methods: Leisure centres records were used to identify patients referred to Living Plus between January 1996 and June 1999. A copy of the questionnaire, a covering letter explanation what the study was about, and a stamped addressed envelope were posted to 245 subjects.

Results: One hundred and eighteen (48\%) responded, $94(79 \%)$ of these patients completed 7 or more weeks of the Living Plus program (completers). Twenty four $(21 \%)$ completed less than 7 weeks of the program, $9(8 \%)$ of these 234 were classed as drop outs, and the remaining $15(13 \%)$ who were not told or contacted about Living plus were classed as non-participants. The most common barrier to participation $(67 \%)$ was "lack of communication" between the patients and Living Plus staff. The most commonly cited reasons for drop out (67\%) was illness. Social deprivation was not found to have a significant influence on uptake or attendance. Physical activity levels between completers, non-participants, and drop outs were not of a significant difference. The majority of patients in each of the groups were not regularly active.

Conclusions: This study demonstrates good uptake of and adherence to Living Plus but improved communication between staff and subjects is required. However structured exercise referral programmes for GPs do not influence long term physical activity levels.

\section{SUBJECTIVE FUNCTIONAL ASSESSMENTS AND THE RETURN TO COMPETITIVE AND RECREATIONAL SPORTS ACTIVITY FOLLOWING ANTERIOR CRUCIATE LIGAMENT RECONSTRUCTION. A RETROSPECTIVE STUDY OF 77 ATHLETES FOLLOWED UP AT TWO TO SIX YEARS POST SURGERY.}

F. Smith.

Objectives: The primary study objectives were to address (a) the return to competitive sports participation within 12 months following surgery, (b) the maintenance of competitive participation at follow up, and $(c)$ the relationship of the level of sports activity at follow up.

Methods: Of 109 selected patients 77 (71\%) responded. All patients were competitive athletes pre-injury and had undergone anterior cruciate ligament $(A C L)$ reconstruction using the transtibial endoscopic technique and either bone-patellar tendon bone or a multiple looped hamstring autograft. Evaluation was carried out at a mean of 43 months (range 24-73) post surgery by a postal questionnaire consisting of the Cincinnati sports activity scale and sports function scales.

Results: At 12 months, $80.7 \%$ of patients had returned to competitive participation of which $88.7 \%$ were competing at pre-injury or higher levels. Of the competitive patients, $74.2 \%$ competing at pre-injury levels at 12 months, were active as such at follow up. At 12 months, $21.8 \%$ of the competitive patients competing at pre-injury levels did so with significant complaints. At follow up, $50 \%$ of patients were active in sports at least four times per week. There was a relationship between sports activity score and the total sports function score at follow up. Male patients had significantly higher sports activity scores $(p=0.0059)$ and overall sports activity scores $(p=0.024)$ compared to female patients. Patients with few functional complaints maintained high levels of sports activity even after discontinuing competitive participation.

Conclusions: The return to competitive participation at pre-injury levels, both at 12 months and at follow up was high provided the appropriate standard of treatment, patient selection, and exclusion criteria were adhered to.

\section{THE LONG TERM EFFECTS OF LOWER LIMB MUSCULOSKELETAL INJURY}

H.M. Holder-Powell. GKT School of Biomedical Sciences, Kings College, London

Background: Injury to the lower limb is common in sport and recreational activities, however little is known of the long term outcome of rehabilitation.

Aim: To assess if any long term decrement in muscle strength, balance, functional activity, and bone mineral density occurs after unilateral lower limb injury.

Methods: The uninjured and injured legs of 48 (11 female) subjects with previous lower limb injuries and a mean time since injury 
of 9.7 years were assessed for: (a) isometric and/or dynamic strength of the quadriceps, hamstrings, and plantarflexor muscles (Kin Com $500 \mathrm{H}$ isokinetic dynamometer); (b) postural sway (Chattanooga balance system); (c) functional sitting to standing and step up/down tests, and (d) bone mineral density (BMD) $(n=10)$ (DEXA, model DPXL).

Results: Significant differences were seen between the injured and uninjured side for: quadriceps ( $p<0.0001)$ and plantarflexors $(p=0.024)$, but not for the hamstring muscles (Holder-Powell HM, Rutherford OM. Arch Phys Med Rehabil 1999;80:717-20); sway index ( $\mathrm{p}=0.012$ ) (Holder-Powell HM, Rutherford OM. Arch Phys Med Rehabil 2000;81:265-8); sitting to standing ( $p=0.002)$, standing to sitting $(p=0.0003)$, step-down functional tests $(p=0.012)$, and $B M D$ $(p=0.017)$.

Conclusions: These studies show that in most subjects, with relatively straightforward lower limb musculoskeletal injury, return to the "pre-injured state" does not occur. Deficits in motor and sensory control appear to remain years after injury. Further study is needed to clarify the effects of specific rehabilitation and training.

\section{EFFECTS OF HEEL-CUPPED AND FLAT ORTHOSES ON SYMPTOMATIC ANTERIOR KNEE PAIN RELIEF}

S. Finch, J. Newton, A. Horwood. Leeds Metropolitan University, Leeds

Purpose: The effect of heel-cupped orthoses compared to flat orthoses, on anterior knee pain relief was investigated.

Subjects: Fourteen symptomatic anterior knee pain patients (eight female, six male, age range 20-44 yr), presenting themselves with Patellofemoral Pain Syndrome, characterised by the conditions: pes anseine bursitis, medial/lateral peripatella retinaculitis, and patellofemoral degenerative joint disease.

Methods: Subjects were randomly assigned to one of two intervention groups: a heel-cupped orthoses group $(n=7)$, and a flat orthoses group $(n=7)$. The assigned heel-cupped or flat orthoses were prescribed to the individual after clinical evaluation. A Visual Analogue Scale was used to assess the subject's pain levels after a two week intervention period.

Results: A two way repeated measures ANOVA test, revealed significant differences between the groups $\left(F_{126}=39.3\right.$ at the $5 \%$ level), and post hoc analysis found significant differences at the $5 \%$ level, for both groups between pre and post-test scores. A significant difference in post-test scores between the two groups $(p<0.05)$ indicated that the pain reduction for the heel-cupped orthoses group was significantly greater than that of the flat orthoses group. Mean pain improvement was $66 \%$ and $51 \%$ for the heel-cupped and flat orthoses groups, respectively.

Conclusions: The results suggest that heel-cupped orthoses elicit a higher level of pain relief than compared to the flat orthoses, in subjects with Patellofemoral Pain Syndrome. This is theorised to be because the heel-cupped orthoses offer greater rearfoot control. This has clinical implications for reduced treatment times of patients with Patellofemoral Pain Syndrome.

\section{HIGH PLANTAR PRESSURES IN CYCLING-THE POTENTIAL FOR INJURY}

R.Watterston. Department of Exercise and Sport Science, Crewe \& Alsager Campus, Manchester Metropolitan University, Manchester

Forefoot pain in cyclists is increasingly common with the new smaller style of clipless pedals and stiffer soled shoes. Hennig \& Sanderson measured plantar pressures in cyclists and found the peak pressures occurred in the first toe and first metatarsal head (Hennig EM, Sanderson DJ. Journal of Applied Biomechanics 1995;11:68-80). These pressures decreased when softer soled running shoes were used.

Six male subjects cycled on a King cycle trainer at a power output of $250 \pm 10$ watts with a cadence of $90 \pm 5 \mathrm{rpm}$. The Pedar system measured the maximum forces and peak pressures in the subject's forefeet. Three different pedal set-ups were compared in seated and standing cycling.

The results showed the maximum forces and peak pressures were occurring around the first toe and metatarsal head. The peak pressures increased as the pedal size reduced, it also dramatically increased during standing cycling where peak pressures in the first metatarsal head were measured at $80 \pm 55 \mathrm{kPa}$.

Meinders, et al found during static loading of the calcaneus local circulation was occluded at $40 \mathrm{kPa}$ (Meinders $\mathrm{M}$, et al. Clinical Biomechanics 1996;11:410-17). The results show that the pressures produced are capable of causing circulatory occlusion as well as nerve compression either of which can lead to pain in the forefoot during cycling. 